\title{
The Use of the MPTP-Treated Mouse as an Animal Model of Parkinsonism
}

\author{
Richard E. Heikkila and Patricia K. Sonsalla
}

\begin{abstract}
The MPTP-treated mouse has proven to be a valuable model of parkinsonism. For example, C57 black mice treated with MPTP exhibit a large decrement in the neostriatal content of dopamine and its metabolites, a marked reduction in the capacity of neostriatal synaptosomal preparations to accumulate $\left[{ }^{3} \mathrm{H}\right]$ dopamine, a large decrease in neostriatal tyrosine hydroxylase activity, a marked loss of nerve cells in the zona compacta of the substantia nigra, and pronounced behavioral deficits. These biochemical, pathological and behavioral deficits are similarly observed in MPTP-treated primates and in humans with idiopathic parkinsonism. A great deal of our current knowledge concerning MPTP has come from experimentation carried out in the mouse.
\end{abstract}

RÉSUMÉ: Utilisation de la souris traitée au MPTP comme modèle animal du parkinsonisme. La souris traitée au MPTP s'est avérée être un modèle précieux du parkinsonisme. Les souris noires C57, par exemple, lorsqu'elles sont traitées avec du MPTP présentent une diminution importante du contenu en dopamine et de ses métabolites au niveau du néostriatum, une réduction marquée de la capacité des préparations de synaptosomes du néostriatum à accumuler la $\left[{ }^{3} \mathrm{H}\right]$ dopamine, une diminution importante de l'activité de la tyrosine hydroxylase dans le néostriatum, une perte importante de cellules nerveuses dans la zona compacta de la substance noire et des déficits comportementaux marqués. Ces déficits biochimiques, pathologiques et comportementaux sont également observés chez les primates traités au MPTP et chez les humains atteints de parkinsonisme idiopathique. Beaucoup de nos connaissances actuelles sur le MPTP proviennent d'expériences effectuées sur la souris.

Can. J. Neurol. Sci. 1987; $14: 436-440$

As is now widely known, 1-methyl-4-phenyl-1,2,3,6-tetrahydropyridine (MPTP) can be formed as a by-product during the "designer drug" synthesis of 1-methyl-4-phenyl-propionoxypiperidine (MPPP), a potent analgesic agent structurally related to meperidine. It was reported a few years ago that the inadvertent ingestion of MPTP, along with varying amounts of MPPP and other agents, caused symptoms of parkinsonism in several young individuals who were likely attempting to simulate the actions of heroin with MPPP. ${ }^{1.2}$ These individuals became afflicted with the classical symptoms of parkinsonism, including tremor, rigidity and akinesia. They were virtually identical in appearance to those suffering from idiopathic parkinsonism except for one major difference: as a group they were considerably younger than those with idiopathic parkinsonism. ${ }^{1.2}$ Moreover, these individuals who self-administered MPTP had low cerebrospinal fluid levels of the dopamine metabolite homovanillic acid and responded favorably to l-dopa and bromocriptine, drugs normally used to treat Parkinson patients. ${ }^{2.3}$ One individual in this group subsequently died of an overdose of drugs, unrelated to MPTP. Histopathological analysis of his brain revealed a striking loss of nerve cells in the zona compacta of the substantia nigra. This loss of cells is the major pathological feature observed in Parkinson patients.

It was also reported that the administration of MPTP, but not of MPPP, caused behavioral deficits, biochemical changes, and neuropathological changes in primates, similar to those observed in humans with idiopathic parkinsonism. ${ }^{4}$ It thus may be concluded that the agent responsible for causing the parkinsonism in the human drug abusers was MPTP. The discovery that a simple substance of this type, administered to experimental animals, or self-administered by humans, can cause neurological deficits which so closely resemble the deficits seen in the parkinsonian patient, has tremendous implications for the etiology of human parkinsonism. It suggests that a similar toxin, endogenous or exogenous, may be involved in the pathogenesis of parkinsonism. This speculation is underscored by two pieces of information. Firstly, the lack of concordance of parkinsonism in identical twins has tended to rule out genetic influences as being causative. ${ }^{5.6}$ And secondly, the pathological changes observed in older primates treated with MPTP even more closely resemble the pathological changes seen in the Parkinson patient than previously thought. ${ }^{7}$ Apparently, most of the early experiments with MPTP had been done in younger primates.

At about the same time as it was shown that monkeys were very sensitive to the dopaminergic toxicity of MPTP, it was also shown that rats and guinea pigs were relatively insensitive. ${ }^{8}$ It was quickly concluded by many that "MPTP works in primates, but that it doesn't work in rodents." However, a few years ago, we demonstrated that MPTP is neurotoxic to nigrostriatal dopaminergic neurons in mice. ${ }^{9}$ Although the mouse is consid- 
erably less sensitive to MPTP than is the monkey, the MPTPtreated mouse exhibits clear behavioral, biochemical and pathological deficits. These deficits, which are in many respects similar to those observed in MPTP-treated primates, are comparable to those observed in human Parkinson patients. A discussion of some of our experience using MPTP in mice forms the basis of the present report.

\section{Materials ANd Methods}

Male C57 black, CF-W (Swiss-Webster), BALB/C, CF-1, and CD-1 mice were purchased from Charles River Laboratories (Wilmington, MA). All animals weighed 20-25 g at the time of testing. MPTP hydrochloride (Research Biochemicals, Wayland, MA) or $2^{\prime} \mathrm{CH}_{3}$-MPTP hydrochloride (synthesized in our laboratory) was administered by i.p. injection at the doses (as the free base) and at the time intervals indicated in the figure or table legends. As indicated, deprenyl hydrochloride (Research Biochemicals, Wayland, MA), pargyline hydrochloride (Sigma Chemicals, St. Louis, MO) or AGN 1133 hydrochloride (gift of Dr. M. Youdim, Technion-Israel Institute of Technology), was administered i.p. approximately $18 \mathrm{~h}$ before administration of the appropriate neurotoxin. The mice were killed one or three weeks later as indicated and the levels of neostriatal dopamine (DA) and its major metabolites, dihydroxyphenylacetic acid (DOPAC) and homovanillic acid (HVA), were measured by high performance liquid chromatography with electrochemical detection. ${ }^{9.10}$

\section{Results AND Discussion}

The mouse has proven to be an excellent animal in which to study MPTP-induced neurotoxicity to nigrostriatal dopaminergic neurons. In our studies with MPTP in the mouse, we have made some interesting observations and have found that there are several important factors which need to be considered in using MPTP to produce a mouse model of parkinsonism. One very important factor is the choice of a dosing paradigm. In our initial experiments in the mouse, MPTP $(30 \mathrm{mg} / \mathrm{kg} /$ injection) was administered in single daily injections over a period of several days. ${ }^{9}$ Under these experimental conditions, this dose of MPTP was approximately one-half of the $\mathrm{LD}_{50}$. More recently, however, we have found that if a given dose of MPTP is administered more frequently, substantially less MPTP is needed to produce an equivalent degree of neurotoxicity. Moreover, neurotoxicity can be induced much more rapidly. The rationale for using shorter time intervals between injections of MPTP is based on the observation that the half-life of $\mathrm{MPP}^{+}$, which is believed to be the ultimate neurotoxin, is approximately $2 \mathrm{~h}$ in the mouse brain. ${ }^{1}$ The data in Figure 1 demonstrate that there are considerable differences in the extent of neostriatal DA depletion in mice which received the same total dose of MPTP $(80 \mathrm{mg} / \mathrm{kg})$, but administered in different doses per injection and at different time intervals. In both strains of mice (C57 black and CF-W), 8 hourly injections of MPTP $(10 \mathrm{mg} / \mathrm{kg} /$ injection $)$ produced an approximate $60 \%$ depletion of neostriatal dopamine (A of Figure 1) whereas 4 injections of MPTP $(10 \mathrm{mg} / \mathrm{kg} /$ injection) administered at $2 \mathrm{~h}$ intervals on two successive days did not significantly affect DA levels in either strain (B of Figure 1). However, a substantial reduction in neostriatal DA was observed in those mice which received 4 injections of

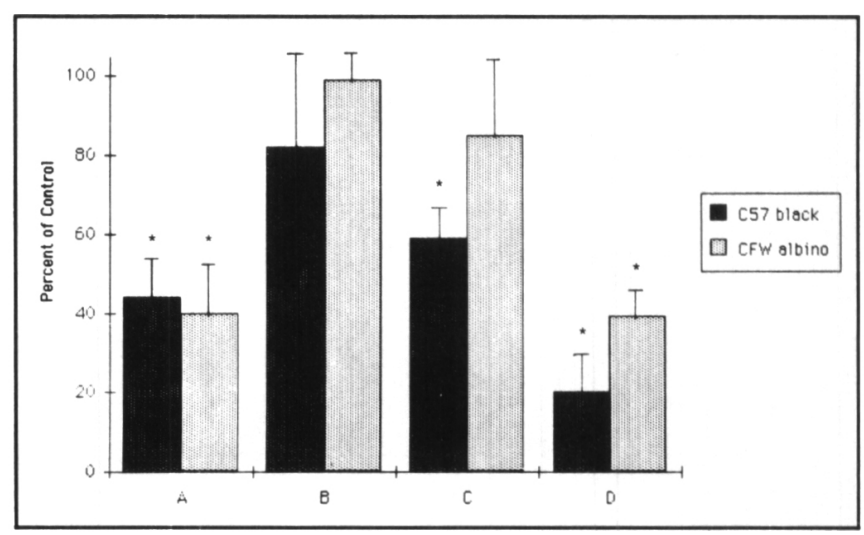

Figure I - The effect of different dosing paradigms for MPTP administration on the extent of DA depletion in mouse neostriatum. Groups of C57 black or CF-W albino mice (6-10 mice per group) received a total dose of $80 \mathrm{mg} / \mathrm{kg}$ of MPTP using one of the following dosing paradigms: A) 8 injections of $10 \mathrm{mg} / \mathrm{kg} / \mathrm{inj}$ ection administered every hour, B) 4 injections of $10 \mathrm{mg} / \mathrm{kg} /$ injection administered at $2 \mathrm{~h}$ intervals with the same sequence repeated the next day, C) 2 injections of $20 \mathrm{mg} / \mathrm{kg} /$ injection administered 6 h apart on two successive days, and D) 4 injections of $20 \mathrm{mg} / \mathrm{kg} / \mathrm{injection}$ administered at 2 h intervals in a single day. The animals were killed one week later and neostriatal DA was measured. The results represent the mean concentration $\pm S . D$. and are presented as a percentage of the mean $D A$ content in their respective control group. The concentrations of neostriatal DA in the untreated control groups were (mean $\pm S . D.): 13.5 \pm 1.2$ $\mu \mathrm{g} / \mathrm{g}$ tissue in C57 black and $12.8 \pm I .1 \mu \mathrm{g} / \mathrm{g}$ tissue in CF.W albino mice. $* P<0.001$ from respective control value. Modified from Sonsalla and Heikkila, 1986.

MPTP at $20 \mathrm{mg} / \mathrm{kg} /$ injection at $2 \mathrm{~h}$ intervals (D in Figure 1) whereas a considerably lesser effect was observed in those mice which received 2 injections of $20 \mathrm{mg} / \mathrm{kg} /$ injection administered $6 \mathrm{~h}$ apart on two successive days ( $\mathrm{C}$ in Figure 1). These findings indicate that both the dose of MPTP administered and the time interval between injections have profound effects on the extent of MPTP-induced neuronal damage. These same variables also affect the extent of mortality. ${ }^{12}$ Clearly the choice of the experimental paradigm is a critical factor in doing experiments with MPTP.

Another observation we have made is that there are marked differences in the sensitivity of different strains of mice to MPTP. ${ }^{12}$ For example, we found that $\mathrm{C} 57$ black mice were very sensitive to MPTP whereas CF-1 and CD-1 mice were relatively insensitive (Figure 2). After 4 injections of MPTP (20 $\mathrm{mg} / \mathrm{kg} /$ injection) at $2 \mathrm{~h}$ intervals, DA was depleted by $95 \%$ in C57 black mice, by $59 \%$ in CF-W mice, and by $38 \%$ in BALB/C mice. In contrast, this same paradigm had no significant effect on neostriatal dopamine content in CF-1 and CD-1 mice. Also note that the effects of MPTP on neostriatal DOPAC content in the different strains of mice paralleled those observed on DA content. In other experiments, we have also observed marked differences in sensitivity to MPTP in Swiss-Webster mice obtained from different suppliers. ${ }^{12.13}$ Although the reasons for the differences in response to MPTP in the various strains of mice or in the Swiss-Webster mice obtained from different suppliers are unknown, our findings indicate that several strains of mice, and particularly C57 black mice, are quite sensitive to MPTP. It is likely that these sensitive strains will prove to be very useful in experimentation with MPTP. These strains can, for example, be used to provide mouse models of parkinsonism. Although less obvious, it is likely that additional important information, perhaps even reasons for the observed differences in sensitivity 


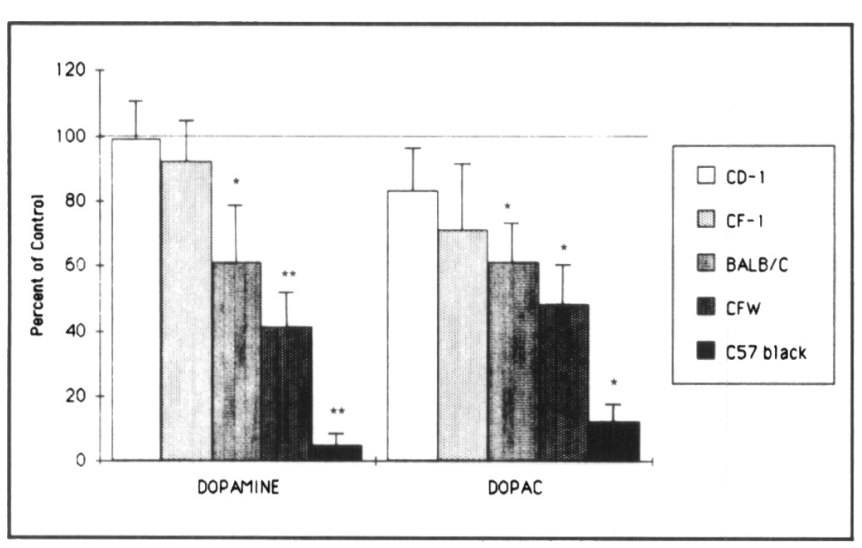

Figure 2 - The effect of MPTP on neostriatal DA and DOPAC in different strains of mice obtained from Charles River Laboratories. Groups of mice from different strains were injected i.p. with MPTP (4 injections of $20 \mathrm{mg} / \mathrm{kg} /$ injection at $2 \mathrm{~h}$ intervals). The mice were killed one week later and the concentrations of DA and DOPAC in the neostriatum were determined. The results represent the mean concentration of neostriatal $D A$ or DOPAC $\pm S . D$. from 4 to 10 mice per group and are expressed as a percent of their respective control value. Control values (mean $\pm S . D$.) in the different strains ranged from $12.0 \pm 1.5$ to $15.8 \pm 2.5 \mu \mathrm{g}$ of $D A / g$ tissue and $1.0 \pm 0.2$ to $1.5 \pm 0.4 \mu \mathrm{g}$ of DOPAC/g tissue. ${ }^{*} P<0.005,{ }^{*} P<<0.001$ from respective control values. Modified from Sonsalla and Heikkila, 1986.

to MPTP, may be obtained from studies utilizing the "insensitive" strains. All of these data suggest that one must exercise great caution before making general statements about the effects of MPTP in mice. Clearly MPTP "works," but how well it works depends on many factors, only a few of which have been discussed above. It is perhaps not surprising that some laboratories may have difficulty in repeating even the simplest of experiments performed in other laboratories. Even within the same laboratory, the effects of MPTP can vary; for example, compare the different effects we have obtained in C57 black mice in the experiments described in Figures 1 and 2.

The neurotoxic actions of MPTP on nigrostriatal dopaminergic neurons in the mouse have been well characterized by several laboratories using different strains of mice and different experimental protocols. For example, it has been shown that in mice treated with MPTP, there are marked reductions in neostriatal levels of dopamine and its metabolites, a greatly diminished capacity of neostriatal synaptosomes to accumulate $\left[{ }^{3} \mathrm{H}\right] \mathrm{DA}$, a loss of neostriatal tyrosine hydroxylase activity, and a substantial loss of nerve cells within the zona compacta of the substantia nigra. ${ }^{9.10 .14-21}$ These same effects have been seen in the MPTPtreated monkey as well as in patients suffering from idiopathic

Table I: A comparison of MPTP-induced neurotoxicity in mice and monkeys.

\begin{tabular}{lcc}
\hline \hline Parameter & Mouse & Monkey \\
\hline Neostriatal DA Content & & \\
Neostriatal DOPAC/HVA Content & & \\
Neostriatal ${ }^{3}$ H-DA uptake & Yes & Yes \\
Neostriatal TH Activity & No & NT \\
Protection by MAO-B inhibitors & Yes & Yes \\
Protection by MAO-A inhibitors & No & NT \\
Protection by DA uptake inhibitors & Yes & Yes \\
Protection by DA depletion & Short-term & Long-term \\
Loss of cells in zona compacta & Yes & Yes \\
Behavioral deficits & &
\end{tabular}

NT $=$ not tested
Parkinson's disease. ${ }^{4}$ For a comparison of some of the effects of MPTP that have been described in the monkey and in the mouse, see Table 1. As was initially found in the mouse, ${ }^{10.14}$ the neurotoxic actions of MPTP are prevented by the pretreatment of monkeys with monoamine oxidase-B inhibitors. ${ }^{22.23}$ In addition, MPTP-induced neurotoxicity in both the mouse and the monkey can be prevented by the concurrent administration of a DA uptake inhibitor. ${ }^{24-27}$ These latter two findings confirm the suggestions based on in vitro observations that two of the critical steps in the neurotoxic action of MPTP are 1) the MAO-B catalyzed oxidation of MPTP to the dihydropyridinium intermediate $\mathrm{MPDP}^{+}$and the subsequent formation of the pyridinium $\mathrm{MPP}^{+28}$ and 2) the active accumulation of $\mathrm{MPP}^{+}$ in dopaminergic neurons by the DA transport system. ${ }^{24}$

It should be emphasized that parkinsonism may be classified as a dopamine deficiency disease. It is clear that both the MPTP-treated mouse and monkey have an extensive neostriatal dopamine deficiency. And in fact, the major biochemical, neuropathological and behavioral deficits observed in MPTPtreated experimental animals and in parkinsonian patients are comparable. It is thus our feeling that the MPTP-treated mouse has been and will continue to be a useful animal model for parkinsonism. Perhaps the major deficiency of the MPTP-treated mouse as an animal model of parkinsonism is that the behavioral deficits in MPTP-treated mice are relatively short-lived. This contrasts with observations made in the MPTP-treated primate, which has been described as being more permanently affected. Reasons for the recovery of the MPTP-treated mouse from its severe behavioral deficits are unclear but are clearly of potential importance and worthy of further study. It should also be stressed that the validity of any animal model for a human disease is dependent upon the strictness of the criteria used to define the model. It is our opinion that much of the disagreement over whether or not the MPTP-treated mouse is a good model for parkinsonism is due to the differences in the definition of the model.

The mouse has proven to be very useful in studies with various MPTP analogs..$^{29-32}$ These studies have been designed in part to provide an understanding of the mechanism by which MPTP exerts its nigrostriatal dopaminergic neurotoxicity. An understanding of those features of the MPTP molecule which are important determinants of neurotoxicity can provide very useful insight into the mode of action of this class of neurotoxins. Of the many MPTP analogs that have been tested in mice, only a fraction have produced any degree of neurotoxicity under the conditions in which they were administered.$^{31-32}$ One of these neurotoxic MPTP analogs, 1-methyl-4-( 2 'methylphenyl)-1, 2,3,6-tetrahydropyridine ( ${ }^{\prime} \mathrm{CH}_{3}$-MPTP), was reported to be a more potent neurotoxin in mice than MPTP itself. ${ }^{30}$ Rather surprisingly, $2^{\prime} \mathrm{CH}_{3}$-MPTP-induced neurotoxicity is not prevented in mice pretreated with selective doses of MAO-B inhibitors, ${ }^{33}$ doses which completely prevent MPTP-induced nigrostriatal dopaminergic neurotoxicity. The data in Table 2 demonstrate that the pretreatment of mice with the MAO-B inhibitor deprenyl at the high but selective dose of $20 \mathrm{mg} / \mathrm{kg}$ fails to protect them against the neurotoxic actions of $2{ }^{\prime} \mathrm{CH}_{3}$ MPTP. Protection against $2^{\prime} \mathrm{CH}_{3}$-MPTP neurotoxicity is observed only when mice are pretreated with large, nonselective doses of MAO-B inhibitors (e.g. see Figure 3). These doses of AGN $1133(30 \mathrm{mg} / \mathrm{kg})$ and pargyline $(75 \mathrm{mg} / \mathrm{kg})$ inhibit the activities of both MAO-B and MAO-A almost completely (data 
Table 2: The effect of a high but selective dose of deprenyl on $2{ }^{\prime} \mathrm{CH}_{3}$-MPTP-induced neurotoxicity in mice

\begin{tabular}{lccccc}
\hline \hline Pretreatment & $2^{\prime} \mathrm{CH}_{3}$-MPTP & n & DA & $\begin{array}{c}\text { DOPAC } \\
(\mu \mathrm{g} / \mathrm{g} \text { tissue })\end{array}$ & HVA \\
\hline Deprenyl & - & 5 & $15.0 \pm 2.8$ & $1.5 \pm 0.4$ & $1.5 \pm 0.2$ \\
- & - & 4 & $15.2 \pm 2.1$ & $1.3 \pm 0.4$ & $1.3 \pm 0.3$ \\
Deprenyl & + & 5 & $4.4 \pm 1.9^{\mathrm{c}}$ & $0.4 \pm 0.1^{\mathrm{a}}$ & $0.6 \pm 0.1^{\mathrm{c}}$ \\
\hline
\end{tabular}

${ }^{\text {a }} \mathrm{P}<.01 ;{ }^{\mathrm{b}} \mathrm{P}<.005 ;{ }^{\mathrm{c}} \mathrm{P}<.001$ as compared to control values.

$\mathrm{CF}-\mathrm{W}$ mice were injected with deprenyl $(20 \mathrm{mg} / \mathrm{kg}$ i.p. $)$ approximately $18 \mathrm{~h}$ before the administration of $2{ }^{\prime} \mathrm{CH}_{3}-\mathrm{MPTP}$ ( 2 injections given $6 \mathrm{~h}$ apart, $17.5 \mathrm{mg} / \mathrm{kg}$ i.p.). The mice were killed one week later and neostriatal concentrations of DA and its metabolites were measured. The results are the mean concentration $\pm S$.D.

not shown). Thus, unlike MPTP-induced neurotoxicity, which is prevented by low and selective doses of MAO-B inhibitors (e.g. deprenyl as low as $1 \mathrm{mg} / \mathrm{kg}$, unpublished observations), $2{ }^{\prime} \mathrm{CH}_{3}$-MPTP-induced neurotoxicity is prevented only with high and nonselective doses of MAO inhibitors, doses at which both forms of $\mathrm{MAO}$ are inactivated. In separate experiments not shown, we have found that a combination of selective doses of clorgyline and deprenyl provided complete protection against the neurotoxic actions of $2^{\prime} \mathrm{CH}_{3}$-MPTP in mice. All of these findings indicate that there is an important role for not only MAO-B but also for MAO-A in $2^{\prime} \mathrm{CH}_{3}$-MPTP-induced neurotoxicity in mice.

The latter observations may have relevance for ongoing clinical studies in which a selective MAO-B inhibitor, namely deprenyl, is being given to newly diagnosed parkinsonian patients "to halt the progression of the disease." These clinical studies are based at least in part on the concept that idiopathic parkinsonism might be caused by an "MPTP-like" molecule. If however, idiopathic parkinsonism were caused by a simple analog of MPTP, for example one like $2{ }^{\prime} \mathrm{CH}_{3}$-MPTP, which is bioactivated not only by MAO-B but also by MAO-A, it is clear that deprenyl treatment would not be effective. One should also consider the possibility that another causative agent, even one very similar to MPTP, might itself be neurotoxic without metabolic activation or alternatively, be bioactivated by a mechanism independent of MAO.

\section{ACKNOWLEDGEMENTS}

This work was supported by grants from the NIH, the Smokeless Tobacco Research Council, the United Parkinson Foundation and the American Parkinson Disease Association. We thank our colleagues including R.C. Duvoisin, W.J. Nicklas, A. Hess, A. Walters, M.V. Kindt, L. Manzino, B.A. Sieber, D. Placenti, R.A. Mayer and S.K. Youngster who have collaborated with us on our ongoing studies with MPTP.

\section{REFERENCES}

1. Davis GC, Williams AC, Markey SP, et al. Chronic parkinsonism secondary to intravenous injection of meperidine analogues. Psych Res 1979; 1: 249-254.

2. Langston JW, Ballard P, Tetrud JW, Irwin I. Chronic parkinsonism in humans due to a product of meperidine-analog synthesis. Science 1983; 219: 979-980.

3. Burns RS, LeWitt PA, Ebert MH, et al. The clinical syndrome of striatal dopamine deficiency: parkinsonism induced by 1 methyl-4-phenyl-1,2,3,6-tetrahydropyridine (MPTP). N Engl J Med 1985; 312: 1418-1421.

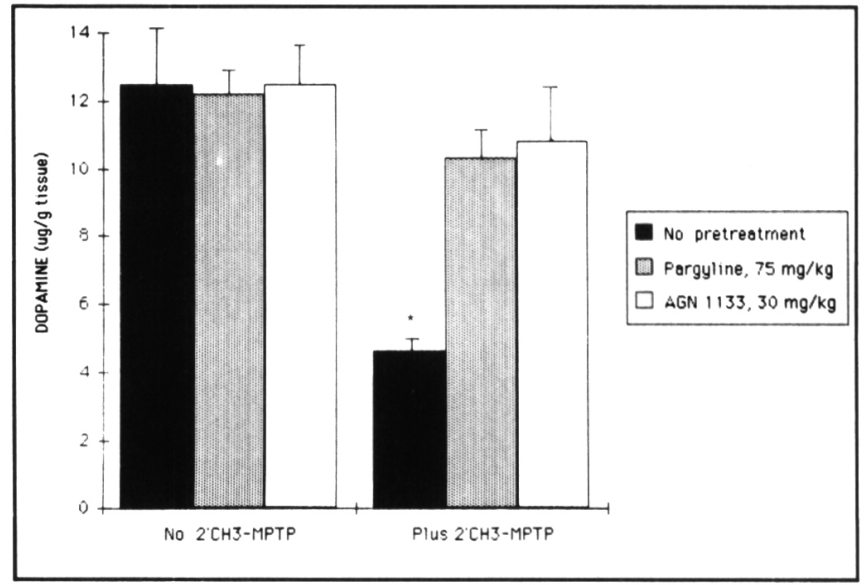

Figure 3 - The effect of nonselective doses of MAO inhibitors on $2^{\prime} \mathrm{CH}_{3-}$ $M P T P$-induced neurotoxicity in mice. Mice were pretreated with pargyline $(75 \mathrm{mg} / \mathrm{kg})$ or $A G N / 133(30 \mathrm{mg} / \mathrm{kg})$ approximately $18 \mathrm{~h}$ before the administration of $2^{\prime} \mathrm{CH}_{3}-\mathrm{MPTP}(2$ injections of $17.5 \mathrm{mg} / \mathrm{kg} / \mathrm{injection}$ given $6 \mathrm{~h}$ apart). The mice were killed 3 weeks later and the content of neostriatal DA was measured. The results are the mean concentration $\pm S . D .\left(n=3\right.$ to 9 mice per group). ${ }^{*} P<0.001$ as compared to control.

4. Burns RS, Chiueh CC. Markey SP, et al. A primate model of parkinsonism: selective destruction of dopaminergic neurons in the pars compacta of the substantia nigra by $\mathrm{N}$-methyl-4-phenyl1,2,3,6-tetrahydropyridine. Proc Natl Acad Sci, USA 1983: 80: 4546-4550.

5. Ward CD, Duvoisin RC, Ince SE, et al. Parkinson's disease in 65 pairs of twins and in a set of quadruplets. Neurology 1983:33: 815-824.

6. Duvoisin RC. Is Parkinson's disease acquired or inherited? Can J Neurol Sci 1984; 11: 151-155.

7. Forno LS, Langston JW, DeLanney LE. et al. Locus ceruleus lesions and eosinophilic inclusions in MPTP-treated monkeys. Ann Neurol 1986; 20: 449-455.

8. Chiueh CC, Markey SP, Burns RS, et al. Neurochemical and behavioral effects of systemic and intranigral administration of $\mathrm{N}$-methyl-4-phenyl-1,2,3,6-tetrahydropyridine in the rat. Eur J Pharmacol 1984; 100: 189-194.

9. Heikkila RE, Hess A, Duvoisin RC. Dopaminergic neurotoxicity of 1-methyl-4-phenyl-1,2,5,6-tetrahydropyridine in mice. Science 1984; 224: 1451-1453.

10. Heikkila RE, Manzino L, Cabbat FS, Duvoisin RC. Protection against the dopaminergic neurotoxicity of 1-methyl-4-phenyl-1. 2,5,6-tetrahydropyridine by monoamine oxidase inhibitors. Nature 1984; 311: 467-469.

11. Markey SP, Johannessen JN, Chiueh CC, et al. Intraneuronal generation of a pyridinium metabolite may cause drug-induced parkinsonism. Nature 1984; 311: 464-467.

12. Sonsalla PK, Heikkila RE. The influence of dose and dosing interval on MPTP-induced dopaminergic neurotoxicity in mice. Eur J Pharmacol 1986; 129: 339-345.

13. Heikkila RE. Differential neurotoxicity of 1-methyl-4-phenyl-1.2, 3,6-tetrahydropyridine (MPTP) in Swiss-Webster mice from different sources. Eur J Pharmacol 1985; 117: 131-133.

14. Fuller RW, Hemrick-Luecke SK. Influence of selective, reversible inhibitors of monoamine oxidase on the prolonged depletion of striatal dopamine by 1-methyl-4-phenyl-1,2,3.6-tetrahydropyridine in mice. Life Sci 1985; 37: 1089-1096.

15. Gupta MD, Felten DL, Gash DM. MPTP alters central catecholamine neurons in addition to the nigrostriatal system. Br Res Bull 1984; 13: 737-742.

16. Perry TL, Yong VW, Clavier RM. et al. Partial protection from the dopaminergic neurotoxin $\mathrm{N}$-methyl-4-phenyl-1,2,3,6-tetrahydropyridine by four different antioxidants in the mouse. Neurosci Lett 1985; 60: 109-114.

17. Schmidt CJ, Bruckwick E, Lovenberg W. Lack of evidence supporting a role for dopamine in 1-methyl-4-phenyl-1,2,3,6-tetrahydropyridine neurotoxicity. Eur J Pharmacol 1985: 113: 149-150. 
18. Sundstrom E, Jonsson G. Pharmacological interference with the neurotoxic action of 1-methyl-4-phenyl-1,2,3,6-tetrahydropyridine (MPTP) on central catecholamine neurons in the mouse. Eur J Pharmacol 1985; 110: 293-299.

19. Wallace RA, Boldry R, Schmittgen T, et al. Effect of 1-methyl-4phenyl-1,2,3,6-tetrahydropyridine (MPTP) on monoamine neurotransmitters in mouse brain and heart. Life Sci 1984; 35: 285-291.

20. Melamed E, Rosenthal J, Globus M, et al. Mesolimbic dopaminergic neurons are not spared by MPTP neurotoxicity in mice. Eur $\mathrm{J}$ Pharmacol 1985: 114: 97-100.

21. Mayer RA, Walters AS, Heikkila RE. 1-Methyl-4-phenyl-1,2,3, 6-tetrahydropyridine (MPTP) administration to C57-black mice leads to parallel decrements in neostriatal dopamine content and tyrosine hydroxylase activity. Eur J Pharmacol 1986; 120: 375-377.

22. Langston JW, Irwin I. Langston EB, Forno LS. Pargyline prevents MPTP-induced parkinsonism in primates. Science 1984; 225 : 1480-1482.

23. Cohen G, Pasik P, Cohen B, et al. Pargyline and deprenyl prevent the neurotoxicity of 1-methyl-4-phenyl-1,2,3,6-tetrahydropyridine (MPTP) in monkeys. Eur J Pharmacol 1984; 106: 209-210.

24. Javitch JA, D'Amato RJ, Strittmatter SM, Snyder SH. Parkinsonisminducing neurotoxin, $\mathrm{N}$-methyl-4-phenyl-1,2,3,6-tetrahydropyridine: uptake of the metabolite N-methyl-4-phenylpyridine by dopamine neurons explains selective toxicity. Proc Natl Acad Sci, USA 1985: 82: 2173-2177.

25. Pileblad E, Carlsson A. Catecholamine-uptake inhibitors prevent the neurotoxicity of 1-methyl-4-phenyl-1,2,3,6-tetrahydropyridine (MPTP) in mouse brain. Neuropharmacol 1985: 24: 689-692.

26. Mayer RA. Kindt MV, Heikkila RE. Prevention of the nigrostriatal toxicity of 1-methyl-4-phenyl-1,2,3,6-tetrahydropyridine by inhibi- tors of 3,4-dihydroxyphenylethylamine transport. J Neurochem 1986; 47: 1073-1079.

27. Ricaurte GA, Langston JW, DeLanney LE, et al. Dopamine uptake blockers protect against the dopamine depleting effect of 1-methyl-4-phenyl-1,2,3,6-tetrahydropyridine (MPTP) in the mouse striatum. Neurosci Lett 1985; 59: 259-264.

28. Castagnoli Jr N, Chiba K, Trevor AJ. Potential bioactivation pathways for the neurotoxin 1-methyl-4-phenyl-1,2,3,6-tetrahydropyridine (MPTP). Life Sci 1985; 36: 225-230.

29. Fuller RW, Robertson DW, Hemrick-Luecke SK. Persistént depletion of striatal dopamine in mice by 1 -methyl-4-(2-thienyl)-1,2,3, 6-tetrahydropyridine (MPTP). Biochem Pharmacol 1986; 35: 143-144.

30. Youngster SK, Duvoisin RC, Hess A, et al. 1-Methyl-4-(2'methylphenyl)-1,2,3,6-tetrahydropyridine $\left(2^{\prime}-\mathrm{CH}_{3}\right.$-MPTP) is a more potent doparninergic neurotoxin than MPTP in mice. Eur J Pharmacol 1986; 122: 283-287.

31. Youngster SK, Sonsalla PK, Heikkila RE. Evaluation of the biological activity of several analogs of the dopaminergic neurotoxin 1-methyl-4-phenyl-1,2,3,6-tetrahydropyridine. J Neurochem 1987; 48: 929-934.

32. Bradbury AJ, Costall B, Domeney AM, et al. The toxic actions of MPTP and its metabolite MPP ${ }^{+}$are not mimicked by analogues of MPTP lacking an N-methyl moiety. Neurosci Lett 1985; 61: 121-126.

33. Heikkila RE, Youngster SK, Sonsalla PK, et al. The role of monoamine oxidase-B (MAO-B) in the dopaminergic neurotoxicity induced by 1-methyl-4-( 2 ' methylphenyl)-1,2,3,6-tetrahydropyridine (2 $\mathrm{CH}_{3}$-MPTP). Soc Neurosci Abstr 1986; 12: 1394. 